\title{
Polite Request Among the Akyem Speech Community in Ghana
}

\author{
Esther Ofosua Totimeh ${ }^{1}$, Lawrence Bosiwah ${ }^{1}$ \\ Dept of Ghanaian Languages \& Linguistics, College of Humanities \& Legal Studies, University of Cape Coast, Cape Coast, Ghana
}

Email address:

estotimeh@yahoo.com (E. O. Totimeh), lbosiwah@ucc.edu.gh (L. Bosiwah)

\section{To cite this article:}

Esther Ofosua Totimeh, Lawrence Bosiwah. Polite Request Among the Akyem Speech Community in Ghana. International Journal of Language and Linguistics. Vol. 3, No. 2, 2015, pp. 76-89. doi: 10.11648/j.ij11.20150302.16

\begin{abstract}
This paper investigates into various ways by which native speakers of the Akyem Twi dialect of the Akan Language of Ghana make polite request and how social variables such as age, gender and socio-economic status influence their request making. An ethnographic research approach to qualitative design was employed and the research participants of twenty were randomly selected using the purposive sampling technique of which their responses from the interview and the observation to the topic problem were submitted to content analysis. The findings indicate that the strategy for polite request is the indirect strategy. Comparatively, the Akyem speech community equally prefers the conventional indirect strategy as the most polite strategy of request speech act as the other speech communities in Ghana. Also, social variables such as age, gender and socio-economic status influence request making yet equal status contradicts some findings in relation to familiarity. Again, Ghanaians have one condition that warrants request which is not part of the existing one; they believe that the individual granting the request should be trustworthy. Moreover, there were new interesting findings in this study.It was foundout that non-conventional indirect strategy has some natural features which make it different from the conventional strategy and more like the direct strategy, even though they are all indirect strategies.
\end{abstract}

Keywords: Request, Politeness, on-Record Indirectness, Off-Record Indirectness

\section{Introduction}

In the Akan society of Ghana, there are linguistic routines which are of greater value to them. Linguistic routines are the sequential organizations beyond the sentence either as activities of one person or the interaction of two or more. These routines include gestures, paralinguistic features, topics and rituals in everyday interaction but the most outstanding ones are greetings, apology, request, gratitude/thanking, and there counting of one's mission because they are encountered daily. These are very important aspects of the Akan language that the society expects members to perform with the highest degree of communicative competence (Agyekum, 2010). A scholar like Hymes (1974) believes that one should have the ability to use language properly and suitably in order to achieve his or her communication goal and he terms it as communicative competence. Therefore, for an individual to perform a speech act such as request, he or she should take certain things into consideration in order to achieve his or her intent. Sociocultural variables like authority, age, and situational setting are supposed to influence the appropriateness and effectiveness of politeness strategies used to realize directive speech acts such as requests. As the influence of these variables may differ from one culture to another, these variations are relevant factors for a person's intercultural communication competence, viewed as his capacity to communicate appropriately and effectively in a foreign language (Garcia, 1996).

\subsection{Statement of the Problem}

Request is an inevitable and ubiquitous social phenomenon. People make requests for variety of reasons, such as asking a favour, getting permission, fulfilling an obligation, and soliciting agreement (Kim \& Wilson, 1994).

In our daily conversation, we make use of some utterances which express our sense of need. These utterances are based on the factors that constitute ethnography of speaking which to some extent affect the choice of words in a speech event. These factors need to be observed properly, and sometimes strictly, especially in performing speech acts which influence human behaviour since language and social organization are 
linked to each other (Fishman, 1972). It is important that the rules of social organization or interaction which affect language choices are observed, especially in expressing speech acts such as request which influence human behaviour to a large extent (Sarfo, 2011). One of such acts which influence human behaviour is the strategies in making request.

Request is a face- threatening act (Brown and Levinson, 1978). By requesting, the speaker impinges on the hearer's claim to freedom of action and freedom from imposition. Due to their inherently face-threatening nature, requests are especially sensitive, and a pragmatic breakdown and this act may easily lead to unintended offence and/or breakdown in communication (Sadler \&Eröz, 2001). Due to its imposing nature, one needs to make it presentable in the ears of the hearer in order to fulfil his / her goal. By requesting one may sustain or terminate a relationship and it may be granted or rejected depending on the way one makes intentions known.

Also, the way one makes a request can be offensive if the person whose request has been declined does not know about how a request is made in the culture of the one who makes it. As native speakers of a particular language, we are aware of its use as one of the most powerful tools for communication. The way we use language not only conveys a social aspectthat we are part of a speech community and share a discourse accent- but also shows the way we are: our personality, our ambitions, our power, our solidarity, etc. All these aspects, among many others, come into play in a conversation.

Speakers of some cultures may tend to use redressive actions but some may not blatantly use redressive actions because they may have to consider some social factors such as relationship and distance with the hearer.

The strategy and linguistic choice of being polite is usually informed by the speaker's cultural norms and knowledge, and it may vary from culture to culture or situation to situation. The complicated interplay of request making, linguistic choice and culture has attracted much crosscultural research (Blum-Kulka, House \& Kasper, 1989; Weizman, 1989; Reiter, 2000; Sifianou, 1992; Rinnert and Kobayashi, 1999).

Due to the assertion made by these scholars, the researchers seeks to find out the linguistic choice and the strategy of being polite in making request in the Akyem speech community. In other words it seeks to explore the knowledge on how a person's utterance will be accepted as a polite utterance and how similar or different it may be from other cultures; will there be any courtesy markers, hedging attached to the utterance or is there any different way of making such a face threatening act, a face saving act.

\subsection{Purpose of the Study}

Generally, the purpose of the research is to give an insight or enlighten non-native speakers of the Akyem dialect about the polite way in which requests are made in the Akyem speech community. It is to study the influence or effects of social variables in request making in the community.Again, the research examines the felicity conditions needed to make an utterance a request in the Akyem community. Specifically, the purpose is to educate us on the ways of making polite request in the Akyem speech community and how different and similar it is to other speech communities in Ghana.

\subsection{Research Questions}

The following research questions will help the researchers to achieve the research objectives:

1. What are the polite strategies in making request among the Akyem people?

2. How does social variables affect request making among the Akyem people?

3. What are the felicity conditions that warrant a particular request among the Akyem people?

\subsection{Significance of the Study}

Generally, the outcome of this study will give a background of the polite way of making requests in the Akan language. This will help non- native speakers to establish good relationships with the Akyem people.

It will also give the substances needed in making an utterance valid to be termed request in the Akyem community.

Lastly, it will also add to the existing literature and serve as a useful material for other researchers interested in this topic.

\subsection{Delimitation of the Study}

This work is delimited to the people of the Akyem community. Specifically, it is restricted to theAkyem people in Kibi who are native speakers of the language. Most research sites are selected due to proximity and easy access to data but theseresearchers selected this site in order to know more and enlighten us about other cultures like the Akyem culture. The Akyem people are part of the Akan speech community. They are found in the Eastern part of the country and they speak the Akyem dialect which is a variety of the Akan language. They also have their way of life; that is their culture of which their way of speaking will not be exempted. Their culture intertwines with other Akan cultures which mean that one might have a general idea about the culture of the Akans by having knowledge of these people.

However, their way of speaking will be different from the other Akan cultures since it is a variety of the Akan language. Thus the study is delimited to the Akyem people because they are the focus of the study. Furthermore, the study focuses on politeness in the strategy of making request in their culture. This is because the politeness in making request varies from culture to culture and the present study seeks to find out the strategies of making polite requests.

\section{Literature Review}

A speech act is an utterance that serves as a function of communication. We perform speech acts when we offer an apology, greeting, request, complaint, invitation, compliment, or refusal. It is an idea proposed by Austin (1962) to refute the idea of early grammarians who believe that a particular 
utterance of a language has one form and one function (one to one mapping). This means that for example, an utterance which has declarative form functions as a statement and cannot function in any other form such as interrogative which functions as a question.

However, Austin (1962) presented a new picture of analyzing meaning of an utterance. Meaning is described in a relation among linguistic conventions correlated with words or sentences, the situation where the speaker actually says something to the hearer, and associated intentions of the speaker. The idea that meaning exists among these relations is depicted successfully by the concept of acts: in uttering a sentence, that is, in utilizing linguistic conventions, the speaker with an associated intention performs a linguistic act to the hearer. For example a speaker tells a listener, 'Can you shut the door?' The speaker uses an interrogative form yet a request that at the end he expects the door to be closed. This is an example of what Austin explains as actions performed through words.

\subsection{Levels of Speech Act}

The utterances used in our daily interactions can be in its natural form yet mean a different thing altogether. Thus, an utterance can be a question, statement, command but might all mean a request; one can have various forms which can be realized as one function. With this, Austin (1962) propounds three levels of speech act which are locutionary acts, illocutionary acts, perlocutionary acts.

Locutionary act is simply a reference to a sentence (grammatical structure) or an utterance with meaning. Thus the act of producing a sentence with meaning; for instance in performing a locutionary act we shall be performing acts such as answering a question, giving some information etc. The propositional content of locutionary act can be either expressed directly or implied; for example a request such as 'I need the money, so I will come there tomorrow' constitutes expressed locutionary act because its propositional content predicts the future act (Austin, 1975). On the other hand, locutionary can also be implied; for instance, if a speaker tells the listener 'I need to pay the children's fees and I need help.' This locutionary act does not predict the future rather it explains the context which is, the speaker is in need of money from the listener.

Illocutionary act is the intention of the speaker in making an utterance or what he or she intent to accomplish. Thus if a speaker says to a listener, 'Ama, pass me the salt, please,' he performs the illocutionary act of requesting Ama to hand over the salt to him or her. These functions can also be termed as illocutionary force of speech act which is the effect a speech act is intended to have on a speaker (Yan, 2012).

Perlocutionary act is the aim of the utterance or expectance of the speaker. It is other times defined as an action or state of mind brought about by, or as a consequence of, saying something. Thus if a speaker says 'Bring me the water,' and this act causes the listener to fetch the water for the speaker, we would say a perlocutionary act is performed. Perlocutionary act is an act performed by saying something and not in saying something. It precedes illocutionary act which gives us the different functions of utterances (Austin, 1962).

\subsection{Identification of Request as a Speech Act}

Searle (1969) attempts to clarify and helps us understand speech act. He comes out with some categories of which he assigns the various speech acts to a particular category. $\mathrm{He}$ groups the categories into four which comprises representatives such as assertions, descriptions, suggestions etc. Commissives includes promises, pledges, threats, vows, etc. Expressives includes apology, condolence, excuses, thanksgiving etc and directives which entail commands, challenges, advice, dares, request etc.

\subsection{Request as a Directive}

Directives are basically intended to get the addressee or listener to carry out an action. Request is a speech act which falls under the category of a directives; which means it gets a listener into an action. Request can be done through some various strategies; thus the direct and indirect strategies. The direct request involves explicitness which is in a form of command and its language is plain yet it is highly cherished and appreciated for the fact that it offers pragmatic clarity; for example, if one requests ' I need a bowl' it explains that the speaker is in need of an item which is a bowl.

The other strategy which is termed as indirect is implicit which is full of vagueness, prolixity, ambiguity and even avoidance but it is more cherished and preferred especially if the subject communicated is face threatening or difficult as request. It is normally based on context or it deals with implication (Obeng, 1998). It is sub divided into conventional and non conventional strategy. The conventional strategy refers to the contextual preconditions necessary for its performance for instance 'I am thirsty' implies that the speaker is in need of water, thus normally if one visits a home and claims 'He is thirsty', usually there is a follow up statement, 'Let me bring you a glass of water' which means the listener understood the request from context. The non-conventional indirect strategy is sometimes referred to as 'hints' since it partially refers to the object depending on the contextual clues; for instance 'You have left the room untidy' implies that 'You should sweep the room' (BlumKulka, House \& Kasper, 1989).

However, between these two strategies, the non conventional is seen to be the most indirect yet most people believe that the conventional is the most polite strategy (Blum-Kulka, 1987).

\subsection{Felicity Conditions of Speech Act}

Linguists characterize the notion of situational inappropriateness in terms of what are called felicity conditions. The basic idea here is that felicity conditions allow us to determine under what circumstances it is appropriate to ask questions, give commands, and so forth. Thus for an utterance to be accepted as a request, promise, 
compliment, warning etc, it should satisfy its felicity conditions (Henderson \& Brown, 1997). For request, one believes that;

$\mathrm{S}$ (Ama) requests $\mathrm{H}$ (Akua) to (cook):

1. S (Ama) believes that $\mathrm{H}$ (Akua) is able to (cook).

2. S (Ama) believes that $\mathrm{H}$ (Akua) is willing to do (the cooking) for S (Ama).

3. S (Ama) wants (the cooking) to be done by S (Akua).

It basically deals with the conditions necessary to make an utterance valid to be termed as a particular speech act such as request. The condition must be that the speaker is certain that the listener would be able to grant the request.

\subsection{Concept of Politeness}

Politeness is basically an attempt made in order to make a person's face look good. It can also be termed as all efforts made to ensure the person feels good or enhances a person`s face (Goffman, 1967). Brown and Levinson (1987) view politeness from two perspectives; negative face and positive face. Negative face is the basic claim to territories, personal preserves, rights to non-distraction-thus to freedom of action and freedom from imposition.

However, one's face can be threatened when an individual does not avoid or intend to avoid the obstruction of their interlocutor's freedom of action. It can cause damage to either the speaker or the hearer, and makes one of the interlocutors submit their will to the other. Freedom of choice is impeded when negative face threatens, affirms or denies a future act of the hearer and creates pressure on the hearer to either perform or not perform the act. Examples are suggestions, request, advice, threats, warnings etc.

Positive face is the positive consistent self-image or 'personality' (crucially including the desire that this selfimage be appreciated and approved of) claimed by interactants. It can be threatened when the speaker or hearer does not care about their actor's feelings, wants, or does not want what the other wants. For instance when an individual's request is granted due to the fact that the other is regarded as less important due to some socio- economic factors.

Politeness in the Akan system moves in line with indirectness (conventional). These two terms are important discursive phenomena in the Akan social interaction. Therefore conventional indirectness is seen to be the most polite and more often is put side by side with the word politeness itself (Blum-Kulka, 1987). Most researches done affirm the fact that speakers of the various speech communities regard the conventional indirectness as a request strategy that saves an individual's face. Therefore, most of the work done in request is based on indirectness which is sometimes replaced with politeness in their research works.

\subsection{The Acronym of Speaking}

Hymes (1974) believes that one's ability to produce grammatically correct sentences is not enough but the appropriate and acceptable use should be a great factor. Thus one can be termed as communicatively competent of a particular language when the manner of usage is appropriate and accepted by the people of that particular community. $\mathrm{He}$ postulated the acronym of SPEAKING in order to help an individual to communicate effectively in a particular community. He also opines that the appropriate and the acceptable use of a language will depend on the context. Thus it will depend on the situation one finds his or herself that will help shape the way he or she speaks. Request is a form of communication and for an individual to achieve his or her aim in request; the researchers believe that one should consider Hymes SPEAKING, which serves as a guide for speaking. He uses some alphabets in his acronym of SPEAKING to define and explain what they stand for.

The first alphabet S stands for setting, scene or situation. Setting refers to the time and place, that is, the physical circumstances and aspects of the situation in which communication takes place whilst scene refers to the abstract psychological setting, or the cultural definition of the occasion (Wardhaugh, 1992). An example is a person seated at a family meeting at home is a physical setting and the social interaction with the other participants at that moment is a scene.

The next is $\mathrm{P}$ which stands for the participants involved in the communication event. Participant's identity includes age, sex, social status, relationship with each other etc. For instance, in requesting, the participants can be equal- equal or equal- unequal. Depending on the socially specified roles, the participants can be referred to as speaker - listener, speaker - hearer, addresser - addressee, and sender - receiver. Here, we are interested in looking at the age, social and economic status of the interlocutors and how they affect both the linguistic and non-linguistic features of the communicative event whether the relationship between participants is symmetrical or asymmetrical.

Also the $\mathrm{E}$ in the acronym refers to end which includes the purpose of the event itself as well as the individual goals of the participant. Thus the expected outcome or objective of the communicative event. For example, a requester expects an addressee to undertake the activity the requester expects of him or her depending on the relationship. A participant who might request from an elderly will add a courtesy marker to the utterance in order to achieve his purpose.

In furtherance, A also stands for acts of sequence; this is the content and form of the discourse: the precise words used, how they are used, and the relationship of what is said to be the actual topic at hand (Wardhaugh, 1992). It can also be defined as the sequence or how speech acts are organized within a speech event and what topic is addressed. For example, during a family gathering, a request can be granted or refused depending on how it was presented to the participants at the gathering.

The next is the tone or manner of how a message is conveyed; thus the $\mathrm{K}$ which stands for key. The message can be carried out in a manner that is serious, gentle, kind, pompous, teasing, mocking, sarcastic, insulting, circumlocutory or precise. Some speakers might request in a 
harsh or an impolite manner, others might be polite. For example, a speaker might say 'I need a pen' which carries a harsh tone. Another person might use the same utterance 'I need a pen, please' which is gentle and polite and seems different from the other utterance.

Moreover, I in the acronym campaigns for instrumentalities. It defines the choice of channel, that is, the medium through which the message is conveyed. The medium can be through a drum, a linguist, dance and a particular variety of a language. For instance, a child can ask for her needs from a father through a mother with the use of a variety of the Akan language such as the Akyem dialect to convey her message.

To add up is the norms of interaction and interpretation which is N. Every society has its own acceptable ways of communication. The norms of communication determine whether a speaker is being polite or impolite towards the addressee. For a speaker to get a positive outcome after a request, he or she should take the norms of the society he or she belongs to into consideration. A speaker can add polite markers such as 'please' to such face threatening speech act as request when requesting for something.

Lastly is $G$, which is genre. It refers to the type of utterance or events. Types of utterances include poems, riddles, sermons, prayers, lectures, judgment and sentencing, libation, etc. For instance, the way a speaker will request from a father at home will be different from a priest request during a libation at the shrine.

\subsection{The Relationship between Speech Act and the Act of Speaking}

Within speech communities, ethnographers must look for 'speech situations', 'speech events', and 'speech acts'. By speech situations, Hymes means socially-contextual situations like 'ceremonies, fights, hunts, meals, and the like' (Hymes, 1974: 56). Speech events occur within speech situations, so for example the pouring of libation is a speech event occurring within a festival (a speech situation). Speech acts are the individual utterances that form the minimal unit of analysis for ethnographies of communication. An example is 'a festival (speech situation) within which we have the pouring of libation (speech event), a request is made through the libation (speech act)' to illustrate the three terms (ibid.). Hymes distinguishes speech acts from grammatical conceptions like sentences, because the meaning, status, and function of a speech act are not solely dependent upon grammatical form. The interpretation of speech acts is equally (at times more) dependent upon the social status and relationship of participants, as well as the immediate context of the utterance, and so 'the level of speech acts mediates immediately between the usual levels of grammar and the rest of a speech event or situation in that it implicates both linguistic form and social norms'.

To help ethnographers of communications frame their investigation of speech acts and events, Hymes offers the mnemonic device of the SPEAKING grid as a heuristic. The SPEAKING grid is perhaps the artifact most associated with
Hymes as his popular legacy. The SPEAKING grid has been widely accepted in the ethnography of communication, and has been further developed into discrete research questions by Hymes' students, Joel Sherzer and Regna Darnell (Sherzer and Darnell, 1972).

\subsection{Politeness Theory}

Politeness is the awareness of another person's 'face' or the means employed to acknowledge the public self- image of a person. It is a system of interpersonal relations designed to facilitate interaction by minimizing the potential for the conflict and confrontation inherent in all human interactions transactions (Lakoff, 1973, p. 34).

In explaining politeness, is the concept of 'face,' the positive social value a person effectively claims for himself by the line others assume he has taken during a particular contact (Goffman, 1967, p. 5).

However, one can threaten a person's face which is normally termed as face threatening act which negatively affects the mutual understanding and social cohesion between participants. Other times, one can also avoid the tendency of threatening one's face even when the speech act such as request is a face threatening one. This bridges the relationship between participants. These theories are propounded by scholars like Leech (1983), Brown and Levinson (1987), Lakoff (1973) and Goffman (1967) who explain the above key terms (face, face threatening act, face saving act) through their theories.

\subsection{The Theory of Face}

One major condition that can help to achieve the desired goal of an utterance is the observance or maintenance of what researchers have called Face, which refers to one's selfesteem which they want to protect (Goffman, 1967). Face relates to how people interact and perceive each other in their daily lives. Goffman claims that everyone is concerned, to a large extent, with how others perceive him/her. Individuals act socially, striving to maintain or project their identity or public self-image. To lose face, therefore, is to publicly suffer a diminished self-image; maintaining face is accomplished by taking a line whilst interacting socially.

According to Brown and Levinson (1987), face is of two types, namely: Positive Face and Negative Face. Positive Face refers to the desire to be liked, appreciated, approved of, or the need to have a positive image accepted by others. Negative face refers to the desire to be unimpeded, imposed upon, and intruded or the need to be free from obligation in one's actions. Failure to observe the face of an interlocutor can mar communication.

\subsection{Face Saving Acts (FSAs)}

Closely related to the theory of Face is the Politeness Principle put forward by Lakoff (1973), and further developed by Brown and Levinson (1987) as well as Leech (1983). Lakoff identifies three politeness maxims for the maintenance of Face or relationships in communication. 
These are: Do not impose, give options and make your listener feel good. Although we have the free will to make any form of request, offer, invite or suggestion, we usually try not to impose on them since one has an expectation: We normally say it in a polite way since we need a positive outcome. In requesting, we generally threaten peoples face, unless it is done in such a way as to still preserve their face.

According to Brown and Levinson (1987), politeness strategies are developed in order to save the hearer's face. They identify four politeness strategies which deal with facethreat: Bald-on-Record, Negative Politeness, Positive Politeness and Off-Record. Bald-On-Record strategy usually provides no effort to minimize threats to the hearer's face: It does not normally recognize the addressee's want of respect. Negative Politeness strategy, which addresses Negative Face, concerns the assumption that the speaker is somehow imposing on the hearer although he acknowledges the hearer's want of face. Positive Politeness strategy recognizes the hearer's desire, interest, want and need to be respected. It therefore addresses positive face concerns, often by showing prosocial concerns for the other's face. Off-Record strategy employs an indirect way of making a demand. It seeks to recognize and respect the hearer's face: It shows little or no threat to the addressee's want of respect and dignity.

Leech (1983), in dealing with politeness, proposes a maxim that we should minimise the expression of beliefs which are unfavorable to a hearer and at the same time maximise those that favour him/her. According to him, this maxim is relevant for dealing with impositives` (speech acts that impose on the listener or addressee). Request can be said can be said to be impositives' in the sense that when requests are made, the hearer has no option than grant them. Other times the social status affects it such that, even though it is an impositives, the hearer can either grant or refuse your request According to Leech, tact and generosity are the two principles that go with impositives'.

The tact principle survives on the maximization of the cost to the hearer, whilst the generosity principle maximises the benefit unto the speaker himself. He further says that the generosity maxim is less powerful in politeness strategies than the tact maxim. Leech further states that politeness focuses more on the addressee than on the addresser. Speakers tend to take negative politeness much more carefully than positive politeness. The major assumptions underlying both Leech, and Brown and Levinson's theories are the same. They both acknowledge that interlocutors have face and need certain principles to guide them in their communication in order to make the communication process successful. The above-mentioned theories of face and politeness provide a basis upon which this paper is built. This is because one cannot rule out Face, FTA and FPA or FSA, as well as the politeness principles, as discussed above, when looking at request as a social act (an act whose performance requires two or more participants (Smith, 1990). All the theories therefore offer a solid foundation for the study of the speech act of request because anytime a request is made it involves face threat.

\subsection{Face Threatening Acts (FTA)}

According to Brown and Levinson (1978), face threatening acts (FTSs) are illocutionary acts liable to damage or threaten another person's face. Performing an FTA is a matter of choice, and people often opt for it in a crisis situation.

Usually in social interactions, behaviours or actions such as commands or orders, requests, disagreements, criticisms, threats, daring, insulting and refusals undermine the face of an interlocutor because they run contrary to the wishes of the hearer. These are what Brown and Levinson (1987) call Face-Threatening Acts (FTAs).

\section{Methodology}

This study focused on the ethnographical approach to qualitative research whereby the researchers stayed with the participants and studied the respondents which was relevant to the study, considering that it allowed the researchers to have face to face involvement with the participants which helped in examining the group's observable and learned patterns of behaviour, customs and ways of life (Harris, 1986). The main goal of the researchapproach was to provide a thick description of the target culture as well as their beliefs and practices to their behaviours, events and activities. For this reason this approach used diverse range of data collection techniques which entailed the indirect participant observation and interviewing which was semi- structured. Due to thistheresearchers had a list of specific topics to be coveredwhich is termed as an interview guide. It did not follow a strict procedure rather it was in a way structured to guide the interviewers. This ensured the study gained indepth knowledge of polite request and made it relatively easy to document the findings without investing in visual aids. It also enabled the researchers to ask further questions in order to check consistency of the informants.

The interview of the study had two main sections; demographic information of respondents (section A) which in a way helped in satisfying the background of the informants and the main questions (section B) satisfying various objectives of the study.

In addition to in-depth interview, the researchers dwelled on indirect participant observation of interaction among the people of the Akyem community as an instrument of gathering data.The researchers recorded responses from informants using both manual writing (paper and pen) and an electronic recorder.

The primary source of data was the Akyems living in Kibi while the secondary sources of data were books, articles, journals, etc. In all, twenty people were interviewed; ten males and ten females which cut across age, gender and other social status. The researchers had a list of questions which were answered by the respondents but the respondents had the right to express their views and opinions on questions which were not asked. In the collection of data, the study considered the recording devices as appropriate for the 
collection of the data and how the collection was done. Qualitative research work deals with a wide range of data including recorded interviews, various types of texts such as field notes, journal, diary entries and documents. Due to this, the study selected some of these devices such as the electronic recorder and field note since the design was a qualitative one.

The researchers used the manual writing (paper and pen) for participants who did not accept the use of electronic recorder. After asking a question, the researchers put down the responds given by the informants in the field note book. The field notebook was also used when the researchersindirectly observed these same twenty participants who were interviewed yet which was not totally passive because the researchers were involved in some activities like chatting with them, as a conduit of getting the people in order to gather the data. The appropriate information was quickly recorded in the field note book when the researchers had information through observation. Moreover, further questions were asked due to the responds by the informants. Other questions were not part but with the responds from the informants, the researchers deem it appropriate to ask questions which were not found on the interview guide but could help in the study. This study used the oral consent form for the illiterate respondent of which the participant did not sign a consent form; therefore the requirement for documentation of the informed consent was not waived. Moreover, respondents who could read and write were provided with consent forms to sign and demonstrate their agreement to woefully participate in the study. The researchers also briefed respondents on their right to withdraw from the interview at any point in time.

\section{Findings}

Table 1. Showing the demographic information of respondents

\begin{tabular}{llll}
\hline Respondents & Sex & Age & Educational Level \\
\hline Respondent 1 & Female & 23 & Basic \\
Respondent 2 & Female & 27 & Basic \\
Respondent 3 & Male & 23 & Primary \\
Respondent 4 & Female & 35 & Basic \\
Respondent 5 & Female & 32 & Basic \\
Respondent 6 & Female & 74 & Basic \\
Respondent 7 & Male & 42 & Tertiary \\
Respondent 8 & Male & 46 & Basic \\
Respondent 9 & Male & 60 & Basic \\
Respondent 10 & Male & 51 & None \\
Respondent 11 & Female & 42 & Basic \\
Respondent 12 & Female & 41 & Basic \\
Respondent 13 & Male & 52 & Secondary \\
Respondent 14 & Female & 31 & None \\
Respondent 15 & Female & 25 & Basic \\
Respondent 16 & Female & 33 & None \\
Respondent 17 & Male & 56 & None \\
Respondent 18 & Male & 29 & Basic \\
Respondent 19 & Male & 35 & Basic \\
Respondent 20 & Male & 38 & Secondary \\
\hline
\end{tabular}

The researchers interviewed twenty natives of the Kibi community. The age of these respondents falls within 23-74; this implies that in some way or the other both the young and the older people of the Kibi community were involved in request making. In terms of education, only one respondent had attained tertiary education. Majority of them had basic education (completed Junior High School) with a few respondents who had primary education and four had none. Most of these respondents were presumed to have basic knowledge of education and had basic knowledge in English to understand some terms in the interview.

It entails the number of respondents interviewed, their sex, age and their educational level which are displayed in table 1 below.

\subsection{The Indirect Strategy}

Some people make request directly while others prefer the indirect strategy but this study was interested in the polite strategy to make request in the Akyem speech community. With this speech community, the most preferred among these two strategies is the indirect strategy of which they displayed the conventional (on - record indirectness) and the nonconventional strategy (off - record indirectness).

This is evident in these responses;

1. 'Can I get a refresher for free since I have boughta lot of items from you' (By observation)

2. 'Should I serve the food in my palms for your daddy? I said this to mydaughter who always wants to be told what to do.' (Respondent 4, age 35)

This implies that the daughter should bring a plate for the father to be served (explanation by respondent)

The first response was observed when a male speaker came to a provision shop to get some items. He requested an item for free because he thought he has bought a lot of things thus he used a polite way to present his intent. The second speaker was a female who was 35 years of age. She used a different form of indirect utterance to request from her daughter to bring her a plate.

Comparing these findings with other related articles such as 'Persian Requests: Redress of Face through Indirectness' byNodoushan (2008), 'Indirectness and Politeness in Mexican Requests' by Felix-Brasdefer (2005), 'Request Strategies: Cross-Sectional Study of Iranian EFL Learners and Australian Native Speakers' by Jalilifar (2009), one would realize that most of the researched participants preferred the indirect strategy in requestive speech act. Thus, the Akyem speech community agrees with the other speech communities such as the Persian, Romanian and the Hebrew that the polite request strategy is the indirect form. Thus, their choices are similar in terms of the strategy in making polite request.

However, it contrasts with Xiao-le (2011)'s research which was exceptional to the other related works of which in his research the explicit group used the direct strategy to show greater progress in the level of politeness through syntactic patterns, internal and external modifications, and the sequence of request components. But the outcome of this study contradicts with Xiao-le (2011)'s findings on the issue of polite request strategy as indirect which in turn confirms what the other scholars such as Nodoushan, 2008; Felix- 
Brasdefer, 2005; and Jalilifar, 2009 concluded in their works.

\subsection{Conventional Indirectness (On-Record Indirectness)}

The conventional indirectness is basically contextual preconditions which aid in performance and Blum-Kulka (1987) terms it as on-record indirectness. Using the polite strategies postulated by Brown and Levinson (1987), we would say that out of the four strategies which are Bald-onrecord, Negative politeness, positive politeness and offrecord, the conventional indirectness falls under the Negative politeness.

The use of the Negative politeness is to help address a Negative Face by acknowledging the hearer's want yet imposing on the person. The conventional indirect entails the imposing features yet the use of conventional polite markers such as 'Please' and conventional indirect 'context' minimizes the imposition. Examples are illustrated in these four responses;

1. 'If you wouldn't mind can I get a change of twenty cedi? (By observation)

1.'I normally explain my situation when I am in need of something from someone so that the person can understand me and give the thing to me.'(Respondent 2)

2. 'Can you take these foodstuffs to your brother?' (By observation)

3. 'I normally request by beginning with please and sometimesI go to the extent by telling the person my problem in orderto grant my request.'(A male speaker)

From the response 'by observation', the speaker needed a change and knew that he was imposing on the listener so he began with 'if you wouldn't mind' then he requested what he needed. The other respondents explained that they often use courtesy markers to express their sense of need from people so they sometimes use 'Please' and other times explain from context or combine the two to request from an individual.

We notice that most respondents hedge at the beginning of the utterance by using 'Please' or use a question form to request for their need. Other times, the conventionally indirect 'context' is used or there is a combination of both the hedge and context to explain to the person. This in turn has clarifiedpartof the quest in this research which is the addition of courtesy marker such as 'Please' to the utterance or the use of contextual base or statement should be put in a question form.

With regards to the question form, this study confirms Felix-Brasdefer (2005) findings which indicated that in the Spanish language, conventional Indirectness is often conveyed by query preparatory containing reference to preparatory conditions.

\subsection{Non-Conventional Indirect (Off-Record Indirect)}

Non- conventional indirect or hints partially depends on contextual clues and it is also referred by Blum-Kulka (1987) as off-record indirectness. Considering this term off-record in the concept of politeness we notice as explained in the theoretical frame work of this study that off-record politeness seeks to recognize and respect the hearer's face by employing an indirect way of demanding yet the outcome shows little or no threat to the individual (Brown and Levinson, 1987).

Considering the responses given on the non- conventional, it is noticed that the end of this strategy might mostly fail in performance. This is because even though Brown and Levinson (1987) claim that the outcome of non- conventional indirect shows little or no threat to the hearer, the responses given in this speech community tells the opposite of their postulation. The following responses prove this situation;

1. 'I cannot fast this morning because you are travelling'.(A 32 year old female speaker)

2. 'Your mother taught you that as a woman; you stay gluedto your bed after six o'clock eeeh'(A male respondent)

The 32 year old female speaker who wanted her daughter to cook for her, requested from her daughter in an indirect manner yet it was face threatening and this could not be excluded from the second respondent who also explained that he requested that her daughter woke up early by using the non- conventional indirect strategy.

Considering these utterances it is evident that the level of vagueness, incompleteness, ellipsis and ambiguity is high in this strategy of which all these mentioned are among the fifteen strategies of off- record politeness (Brown and Levinson, 1987). Also, the use of such utterances does not only leave the listener to think, to a certain angle it tests the intelligence of the listener. As a result, if the listener is unable to interpret and perform, the face is threatened since he or she might think differently which might cause the requester to either shout at the individual or use the direct strategy.

In terms of completeness we see that the meaning is left to the hearer at the locutionary level as in 'Is it a question or a mere statement' if the hearer does not get it right then it means that there will be no performance. If we relate this to Hymes acronym of SPEAKING and pick out ' $E$ ' which is 'END,' we would say that the purpose of the communication has failed because there is no performance at the end of the communication. This is because the utterances are vague and have different meanings.

Moreover, considering the levels of speech act, we will notice that the hearer or the performer will be left at thelocutionary level where he may comprehend these utterances as mere statement or question.

\subsection{The Effect of Social Variable on Request Making}

In any form of address, there are social variables that influence the speech event. These variables can condition the type of relationship that exists between people in a society. The existence of such social variables also reflects the values and social norms in the society., these social variables have the advantage of ensuring co-existence and peacefulness in the society. Also, Lorenzo-Dus and Bou-Franch (2003) asserted in their research that one cannot base on a social factor to determine language use rather other social variables 
should be considered as simultaneously relevant. This section discusses how social variables such as age, gender and social status influence request among the people of the Akyem community.

\subsection{Polite Request Strategy Based on Age}

This section briefs us on how a social variable such as age can affect the request making in the Akyem community. It grouped the headings as adult to child, child to adult and equal status. It uses some concept explained in the conceptual frame work and face saving and threatening theory to explain the findings in this section. The outcome is compared with the findings of Felix-Brasdefer (2005).

\subsection{Child to Adult}

Considering ' $\mathrm{N}$ ' in Hymes acronym of SPEAKING which deals with the 'NORM' of a society, this study found that age counts a lot regarding the way one speaks in the Akyem speech community. Most respondents kept on using the society and the elderly in their utterances since the society gives credit to the elderly on the topic of politeness. These are some responses;

1. 'A person who comes from a good home and is well brought upunderstands that when you are talking especially to an elderlyperson, the word 'Please' should flow in your speech like water.I will see one as a disrespectful person if a child commandsme to do something for him or her' (Respondent 12)

2. 'It is uncalled for to use such a commanding expression especiallyto older people because our society is against that.'(Respondent 18)

These respondents believe that as child you should avoid the use of a direct strategy or non-conventional when speaking to an adult. This implies that the respondents see the direct and the non- conventional indirect as a face threatening rather than face saving because the adult individual listener will feel disrespected.

Considering these utterances, one will notice that there is the issue of power which contributes to these utterances; if nature grants you the biological status to be an older person, you tend to enjoy this privilege which is the power over the young in terms of speaking manners. Thus if you are young and you talk to an elderly person without hedging or using the conventional indirect in such a face threatening speech act like request, you are seen to be disrespectful in the Akyem community; thus Akan community in general believe that using the conventional indirect shows you are respectful as the respondents have explained in their responses. Nodoushan (2008) found that social distance triggers indirectness in requestive speech acts (RSAs) and this study confirms that in the Akyem community social distance counts in request making since the society has created a distance between a child and an adult.

\subsection{Adult to Child}

However, the issue of using a polite request strategy for a young person from the elderly was less said in the issue of polite request. Most of the respondents said that they control their children and that since they are children, they must grant the request. Due to this, they mostly use the direct strategy and the non- conventional for the young. Let's read what these respondents said;

1. 'When I need something let's say water, I would sayKofi fetch the water for me' (Respondent 15)

2. 'Get me the bowl' (By observation)

3. 'Kwadwo, go and get me the chair' (Respondent 19)

4. 'Won't we bath today in this house?' (By observation)

5. 'I should pour the oil in a basket.' (Respondent 14)

Considering these utterances the study noticed that indeed there is a sense of power in these utterances and the young cannot use such utterance on the elderly as it would be unaccepted in this speech community since the name elderly moves with the power to control the young and thus using these face threatening strategies for the young is accepted in the Akyem community. One can use the non- conventional and the direct strategy for a younger person; one can request the item directly as 'get me the bowl' or can use the address term such as the name of the performer and the request will follow as in;

'Kofi fetch the water for me.' (By observation)

Using Hymes acronym ' $\mathrm{P}$ ' as in participants, one can say that the relationship between participants can be close or distant; from the responses above one will notice that the Akyem society has created a distance between the young and the old; It has also given power to the elderly over the young.

\subsection{Age Mate}

Considering the participants of equal status, respondents insisted on the use of the conventional indirect strategy on the issue of request. These are their responses;

1. 'A co-tenant asked of pepper from me and I didn't likethe manner she asked so I told her I do not have; I thinkthat if you need something, it depends on how you speak to the person. Even if the person does not have she might evenhelp you get some or feel bad of not getting it for you because of the way you presented your issue.' (Respondent 17)

2. 'No you do not keep your pay in my pocket so you cannot command me to do something for you' (A male speaker)

The first respondent explains that a co- tenant asked pepper from her and the manner she presented it didn't go down well with her so she refused and concluded that if one needs something from someone one should speak well in order to get the thing. Such response is not different from the second one who says one does not keep money in his pocket so one cannot command him to do something for him.

This study noticed that even though equal status mostly brings about familiarity as stated in Nodoushan (2008) findings that solidarity enhances addressor's inclination towards directness in request speech act, speakers of this community insist that one uses either a playful manner to ask or one uses the conventional indirect; meaning that the 
Akyem speech community disagrees with the Persians on this assertion by Nodoushan (2008).

\subsection{Polite Request Based on Gender}

Gender is the social construct that enables society to place certain people into the category as either male or female. It can be differentiated from sex which is the biological construction of an individual; thus it is society which determines who should be a male or female. Among the people of Akyem, request is issued from a male to another male, male to a female, female to another female and from a female to a male. Most of the respondents were of the view that such distinctions were necessary. The study noticed that the issue of patriarchy in our various societies was displayed; the females have accepted what society has imposed on them as subordinate while men have the power over them and they consider such power when they need something from the men. The men less consider such conventional strategy when they need something from the women.

\subsection{Male to Male}

Males are seen to have power in our society and thus since each male is given this privilege, there is the need for respect for each other. In the Akyem community, it is noticed that men usually use the conventional indirect strategy for their fellow men. The example given from the data is;

'Can I worry you a bit; please I need your car battery to start my car' (By observation)

This male speaker had his car stopped at the station and needed another battery so he had to request from another driver, and he expresses his intentions by using a polite manner to ask from a colleague male. He uses the negative politeness as explained by Brown and Levinson who says that one uses such form which imposes on one yet in a polite manner.

\subsection{Male to Female}

Men displayed their power on the issue of request when they were requesting from females. They mostly do not explain their situation and the extent they can go is to add the hedge word 'please' to their utterance. This is because they believe that women understand situations and are easily convinced so they do not need to go that far of explaining to them.

This is illustrated in the response below;

1. 'I need some money I will pay you back in a month time'(A male speaker)

2. 'A woman is passionate so if I want something, I willjust ask her and she will give me. (Respondent 8 )

These utterances explain that in the Akyem community, men tend to enjoy the power bestowed on them. Therefore even in such a face threatening situation as request, men tend to minimise the polite talk when referring to their females. Comparing this finding with Al Murani, and Binti (2010) findings, we will notice that the perception of men in the Akan system is different from the Yemeni Arabs who tend to use the indirect form for their females which also affirms Memarian (2012) whose findings revealed that culture has similarities yet can also have some differences which this study has unveil; which is the difference in how the societies portray men and women in terms of request.

\subsection{Female to Female}

This study noticed that when a female need something from their fellow female, they either use the playful manner of use the conventional in the indirect. Example is illustrated in the following;

1. 'Oh I need some items, you know already that when our children re-openswe need to get them some provisions for school' (By observation)

2. 'As for my fellow woman she understands us so I don'thave to talk much.' (A Female Respondent)

This woman came to a provision store to get some few items on credit and she used such a playful expression and made it look like it is a usual thing that mostly happens, of which the one to grant the request sometimes falls a victim. So the woman requesting terms it as a usual thing that happens so she should help her.

\subsection{Female to Male}

Females are portrayed as weak and subordinates as compared to men in the society. The study noticed that it reflected in their expression of need when the men are to grant them. Most females said that they feel shy when they need to ask from the males. This is shown in the response;

'Mmm, I feel shy of men in general so if I am to ask of something from a man I must use a polite way to say it. (A female speaker)

The respondent said she is shy of a man and this study believes it might be due to how society portrayed women. The respondents in the Akyem community expressed their thought on the issue of gender. Respondents expressed different ideas on polite request on the issue of gender. The women tend to use polite request when asking from a male and use a playful manner when asking from a female. The men rarely used the polite manner for the women and express polite utterance in reference to the men.

\subsection{Polite Request Based on Social Status}

Most respondents attested to the fact that whether a person is of higher status or lower status (economical and educational) one has to speak to each in a polite manner. This is because people of higher status are well respected in the society and going to them is a difficult thing to do because they feel shy of them. They also believe that one cannot do what the person of the lower status can do, that is the reason you need his or her help so you need to respect them as well.

1. 'I once needed a job for my daughter so I went to see a manwho is well respected in our society. When I got there Ikneeled down but he asked me to get up else he will notlisten to me. Later I pleaded with him and he promisedto give my daughter a job. I put all shyness 
away becauseI needed it badly.' (Respondent 11)

2. 'Hmmm, it is very difficult. For such a person I thinkthrough for about one week because I feel shy and it is noteasy to go to such a person. When I get there, I plead with himand explain my situation to him so that I will be understood.'(A male speaker)

3. 'I needed someone to weed my backyard for me and the manwas pleased with the way I talked to him and even consideredmy price when I bargained with him. I knew I couldn't weedmyself that is the reason I needed his help so next timeif I need help again he will come' (Respondent 5)

4. 'My porter here is older than I am and I pay him but itdoes not mean I can talk to him anyhow because I cannotdo the work he isdoing. He is the expert.' (Respondent 9)

The social factors such as distance come into this section. This is the reason this study thinks that the respondents talk of shyness and thus prepare so well to meet such people. But it seems most people of such status also speak to people of lower status in a polite manner regardless of their position. Nodoushan (2008) clearly stated in his findings that distance triggers indirectness in requestive speech act and in this finding it supports the fact that it triggers indirectness since the Akyem speakers normally feel shy and prepare so much to meet with person.

\subsection{The Felicity Conditions that Warrants a Particular Request}

Most respondents responded to this issue on four key concepts; distance, trust, the ability of having and the capability of granting the targeted item.

With these concepts; distance, trust and the tendency of having and the capability of granting the request, some respondents talked about familiarity; the reciprocity where persons granting the request also request from the speakers when the need arises. Other times based on trust; thus the person would not spread your problems with others but keep it a secret. Also they believe that the person to grant the request has the need and also would grant the request. Most respondents added that they are often not worried or disappointed because if the person has, it would be granted and the secret of their problem would be kept. For example

1. 'I request from someone whom am close to and have thiskind of give-and-take relationship with' (Respondent 16)

2. 'I request from someone who is free with me and close to me'(Respondent 12)

3. 'I believe he can give me what I want and also think that hehas the capacity. I am close to this person so I ask anytimeI am in need and she also does same. If the person does not getit for me I am not sad or worried because I know if it is thereI will get it' (Respondent 14)

4. 'If you need something you go to someone you can trust andbelieve that your request will be granted. There are somepeople you will go to but they will not give you yet yoursituation will be out there. Others might notget some foryou but will keep it a secret. (Respondent 9)

Comparing with the felicity conditions for request discussed in the conceptual framework, where it was discussed that

1. $\mathrm{S}$ should requests $\mathrm{H}$ to do something

2. $\mathrm{S}$ believes that $\mathrm{H}$ is able to do

3. $\mathrm{S}$ believes that $\mathrm{H}$ is willing to do $\mathrm{A}$ for $\mathrm{S}$

4. S wants A to be done.

We will notice that the findings confirm the above and that further explanation with its effect is also seen in the respondents 'responses. Also, this study has found the fifth condition which;

5. $\mathrm{S}$ believes that $\mathrm{H}$ will not leak $\mathrm{S}$ problem to a the third party $\mathrm{T}$.

\subsection{Other Interesting Findings Based on Indirect Strategies}

This section enlightens us on the issue of indirectness compared with politeness. A research which was conducted by Blum-Kulka (1897) who through countless research on polite strategy in regards to request decided to compare how similar or same these two are in terms of request because most findings asserts the indirect strategy as the preferred strategy in terms of request.

However, this study argues against the fact that BlumKulka should have being specific with his form of indirectness since they are two forms and also considered the preference of speakers before comparing indirectness with politeness. His title made him to conclude that indirectness does not necessarily mean politeness and this study has found the reason he believed so. This interesting finding is discussed into details in the following sub heading.

\subsection{Conventional Indirectness as Politeness}

Politeness is all efforts made to ensure that a person feels good or it enhances a person`s face (Goffman, 1967). Politeness in the Akan system moves in line with the conventional indirectness of which these two terms are important discursive phenomena in the Akan social interaction (Obeng, 1998). The Akyem speakers selected not just the indirect strategy but they were specific with the most polite strategy which is the conventional indirect strategy.

The conventional indirectness strategy (CI) is full of implication and it is often used to sound polite and to save the face of the hearer. The respondents explain that such strategy helps the listener to understand the requester's situation to grant the request. Others also believe that using the conventional indirect strategy shows that one is respectful. These assertions are evident in the following response;

1. 'I believe that the way you talk defines you and that if I am in need of something from someone,

I understand the person is not obliged under any circumstances to grant me my need, so if I want the individual to grant my request, I must request it in a way that will be pleasing to the ears; as for me I sometimes use please and other times too I explain my situation and plead with the 
person to grant me my request.'

This is a sixty year old male respondent who thinks that a person is defined by the way he or she talks. He also believes that using the conventional strategy implies that one is respectful and he uses the conventional in order to explain his situation better and in a polite manner.

However, due to the selection of the indirect strategy by most speakers of other various speech communities, BlumKulka (2008) compared indirectness strategy with politeness and titled his work 'Indirectness and politeness in Request: same or different?' of which this study is pointing out that he was not specific with the type of indirect strategy to be compared with politeness. Blum-Kulka also said that indirectness does not mean politeness which this study thinks that if he was specific his assertion would not hold.

Considering the nature of both strategies discussed earlier, one would notice that the conventional strategy is the best indirect strategy to be compared with politeness since most of the speakers in the other speech communities such as Persian, Romanian and the Hebrewdid not only preferred the indirect strategy but were specific with the type of indirect strategies which was the conventional, of which this study has also found among the Akyem speech group.

This study also believes that Blum-Kulka (1987) disagreed on the issue of indirectness and politeness as not being same because of the nature of the non- conventional strategy which is the most indirect yet avoided by speakers (Blum-Kulka, 1987). One would realize in the responses below that the non- conventional strategy depends on a hint. Meaning if the person does not get the hint it is either the requester loses or the one to grant it will be offended because one has to think through first before there will be a performance.

As the levels of speech act explains; at the locutionary level, one is exposed to the sentence or the grammatical structure; the illocutionary level is the intention of the speaker to make a request while the perlocutionary is the act of performance out of what is said. This response from a respondent explains this situation further.

1. 'Should I serve the food in my palms for your daddy? I said this to my daughter who always wants to be told what to do.' This implies that the daughter should bringa plate for the father to be served. (Respondent 4; explanation by respondent)

We will notice that such utterances above can be understood by logical thinking. This means that most people will understand the various utterances at the locutionary level which might cause failure in performance (perlocutionary level). Moreover, the face of the hearer is threatened because the hearer's ability to think is undermined. Therefore this study thinks the conventional is the same as politeness due to the outcome of these responses.

\subsection{Other Interesting Findings based on Social Status}

There are other respondents who raised the issue of setting the pace by sounding polite to their children rather than using the direct and non- conventional indirect form to request from their children to do something for them. These are their responses;

1. 'In the past, my mother use to tell me the right thing to do by illustrating it to me like what you asking me about, request is something that usually happens and in one way or the other one will need help; my mum never commanded me to do something for her. I did same to my children; I will teach you the right thing to learn by illustrating it.' (A female speaker)

2. 'I use to command my children when I am in need of something but now I have stopped because I want to teach them how to speak politely so I normally plead with them when I am in need of something. I have demonstrated it to them so I expect them do same so if you are an older person I believe you should speak politely too.' (Respondent 3 )

It seems that there has being responses from the young which might be that they do the opposite of what is expected of them in terms of request, so if the child goes against the norms of the society, reference is given to their parents that they did not raise them well. Thus some elderly believes that it is time parents speak politely to the young so they follow them.

\section{Conclusion}

Due to the outcome of the results and findings, the study states that the Akyem people and the Akans in general prefer the conventional indirect strategy as a polite request strategy; one can use the hedge marker 'Please', ask in a question from or can also explain the situation from context depending on the degree of the request. This confirms the question that there is a polite strategy of request speech act in theAkyem speech community and their choice is similar to the other speech communities and also confirms the results of other related articles in this field which also found that the conventional indirect is the most polite strategy.

Also, the findings conclude that social variables such as age, gender and social status affect request making. It is mostly intense when referring to the elderly, males, persons of both higher and lower statuses. Polite way of speaking is related to a group of people; the elderly, men and age mate. Nodoushan (2008) found that social distance triggers indirectness in requestive speech acts (RSAs) and this study confirms that in the Akyem community social distance counts in request making since the society has created a distance between a child and an adult. However, it contradicts with Nodoushan findings from the angle that equal status brings about familiarity but they tend to either use the conventional indirect or a playful manner to request.

The felicity conditions that warrant request strategy in the Akyem community is distance,the trust of not leaking the problem to a third party and the tendency of having and the capability of granting the request. The people of the Akyem community do not request from anyone but they consider the person before approaching the individual to request from him or her. This confirmed the four steps explanation and elaboration given on the general felicity conditions of request 
in the theoretical framework and has added to the existing literature which the trust that it will not be leaked to a third party.

Moreover, there are new interesting findings in this study. The study concludes that the non- conventional is the opposite of the conventional. The nature of the nonconventional has made speakers of the various speech communities to avoid its usage as a polite form even though it carries the most indirect features. It can also be linked to Blum-Kulka's assertion as the reason he said indirectness does not necessarily mean politeness. Moreover this also confirms the reasonSofwan and Rusmi (2011) indicated in their findings that teachers utilized the conventional indirect, followed by the direct strategy and then the nonconventional strategy.

Also, there is a new practice from the minority in the Akyem community who claims that they would abuse the privilege of power over children that the society has bestowed on them by being polite to the young to serve as a ground of illustration to the young.

\section{References}

[1] Agyekum, K. (2010). The Sociolinguistics of Thanking in Akan. NordicJournal of African Studies 19(2): P.77-97.

[2] Al-Marrani, A., \&Binti A. (2010). Polite Request Strategies by Male Speakers of Yemeni Arabic in Male-Male Interaction and Male-Female Intercultural Encounters. Journal of Defense Resources Management No. 2 (2).

[3] Austin, J.L. (1962), How to Do Things with Words: Oxford: Oxford University Press.

[4] Austin, J. L. (1975). 'A Taxonomy of illocutionary Acts,' in: Gunderson, K. (ed), Language, Mind and Knowledge. Minneapolis, Vol.7.

[5] Blum-Kulka, S. (1987). Indirectness and Politeness in Requests: Same or Different?Journal of Pragmatics P,11 (pp131-146) North-Holland.

[6] Blum-Kulka, S. House, J. \& Kasper, G. (Ed.). (1989). Cross cultural pragmatics: Requests and apologies. Norwood, NJ: Ablex Publishing Corporation.

[7] Brown, P., Levinson, S. (1978). Universals in language usage: Politeness phenomena. In E. N. Goody (Ed.), Questions and politeness: Strategies in social interaction (pp. 56-289). Cambridge: Cambridge University Press.

[8] Brown, P, Levinson, Stephen C. (1987), Politeness: Some universals in language usage, Cambridge University Press, Cambridge.

[9] Félix-Brasdefer, J. (2005). Indirectness and Politeness in Mexican Requests. Selected. Proceedings of the 7th Hispanic Linguistics Symposium

[10] Fishman, J. A. (1972). The sociology of language. In: P. Gigliolo (ed.), Language and social context (pp.45-58). London: Penguin Education.

[11] Garcia, C. (1996). Teaching speech act performance: Declining an invitation. Amsterdam/Philadelphia: John
Benjamins Publishing Company.

[12] Goffman, E. (1967). International ritual: Essays in face-toface behaviour. Garden City, NY: Doubleday.

[13] Harris, P. (1986). Designing and reporting experiments. Buckingham: Open Univeristy press. BF200.

[14] Henderson, G .E.,\& Brown. C. (1997).Glossary of Literary Theory. Toronto: University of Toronto English Library press.

[15] Hymes, D. (1974). Foundations in sociolinguistics: An ethnographic approach. Philadelphia: investigators. The Qualitative Report, 15(3), 754-760. Retrieved from http://www.nova.edu/ssss/QR/QR15-3/qid.pdf.

[16] Jalilifar, A. (2009). Request Strategies: Cross-Sectional Study of Iranian EFL Learners and Australian Native Speakers. Vol. 2.No1.

[17] Lakoff, R. (1973). The logic of politeness or minding your $p$ 's and $q$ 's Papers from the Ninth Regional Meeting of the Chicago Linguistics Society (pp 292-305).Chicago: Chicago Linguistics Society.

[18] Kim, M.-S., \& Wilson, S. R. (1994).A cross-cultural comparison of implicit theories of requesting. Communication Monographs, 61, 210-235.

[19] Lakoff, R. (1973). The logic of politeness or minding your p`s and q's Papers from the Ninth Regional Meeting of the Chicago Linguistics Society (pp 292-305).Chicago: Chicago Linguistics Society.

[20] Leech, G. N. (1983).Principles of pragmatics. London: Longman.

[21] Lorenzo-Dus, N. and Bou-Franch, P. (2003).Gender And Politeness: Spanish and British Undergraduates'Perceptions of Appropriate Requests. In: Género, lenguaje y traducción, José Santaemilia (ed) (2003) Valencia: Universitat de Valencia/DirecciónGeneralde la Mujer, pp. 187-199.

[22] Memarian, P. (2012). Request strategies in English by Iranian graduate students. Unpublished dissertation: The Eastern Mediterranean University.

[23] Nodoushan, M. A. S. (2008). Persian requests: Redress of face through indirectness.Iranian Journal of Language Studies (IJLS), Vol. 2(3), (pp. 257-280)

[24] Obeng-Gyasi, S. (1998). Apologies in Akan Discourse. Journal of Pragmatics

[25] Reiter, R. M. (2000). Linguistic politeness in Britain and Uruguay. Amsterdam / Philadelphia: John Benjamins Publishing Company.

[26] Rinnert, C. \& Kobayashi, H. (1999) Requestive hints in Japanese and English. Journal of Pragmatics, 31, 1173-1201.

[27] Sadler, R. \&Eröz, B. (2001).I refuse you: An examination of English refusals by native speakers of English, Lao, and Turkish. University of Minnesota: CARLA

[28] Sarfo, E. (2011).Variations in Ways of Refusing Requests in English among Members of a College Community in Ghana. African Nebula.

[29] Sifianou, M. (1992).Politeness phenomena in England and Greece: A cross cultural perspective. Oxford: Clarendon Press. 
[30] Searle, J. L.(1969). Speech Acts. Cambridge: Cambrigde University Press.

[31] Searle, J. L.(1969). Speech Acts.An Essay in the Philosophy of Language. Cambridge: Cambridge University Press.

[32] Sherzer, J. \&Daenell, R. (1972) 'Outline field guide for the ethnographic study of speech use', in J. J. Gumperz and D. H. Hymes (eds) Directions in Sociolinguistics: The ethnography of communication. New York: Holt, Rinehart, and Winston. Pp. 548-54.

[33] Smith, B. (1990). Towards a history of speech acts, meanings and intentions: critical approaches to the philosophy of John R. Seale (pp 29-61). Berlin/New York: de Gruyter.

[34] Sofwan, A., \&Rusmi. (2011). Therealisation of request strategies by non- native speakers of English. Ragam Journal PengembanganHumaniora Vol.11 No.2.
[35] Wardhaugh, R. (1992). An introduction to sociolinguistics (2nd ed.). USA: Blackwell.

[36] Weizman, E. (1989). Requestive hints. In S. Blum-Kula, J. House \& G. Kasper (Eds.).Cross-cultural pragmatics: Requests and apologies. Norwood, NJ: Ablex Publishing.

[37] Xiao-le, G. (2011).The Effect of Explicit and Implicit Instructions of Request Strategies Intercultural Communication Studies XX: 1.

[38] Yan, H. (2012). The Oxford Dictionary of Pragmatics. Oxford University Press. 